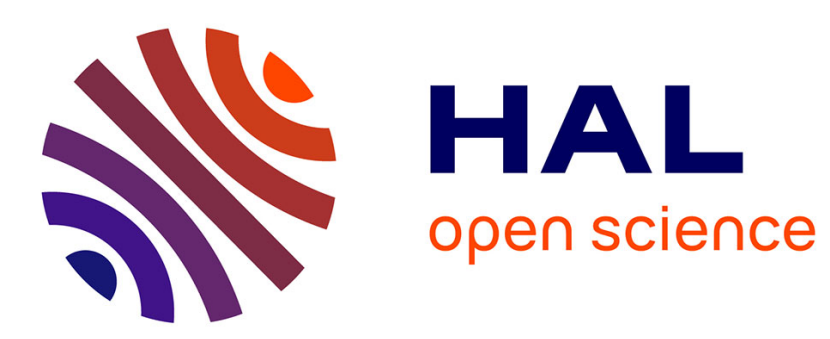

\title{
Effect of the Hydrogen Induced Degradation of Steel on the Internal Friction Spectra
}

\author{
E. Lunarska, Y. Ososkov, Y. Jagodzinski
}

\section{To cite this version:}

E. Lunarska, Y. Ososkov, Y. Jagodzinski. Effect of the Hydrogen Induced Degradation of Steel on the Internal Friction Spectra. Journal de Physique IV Proceedings, 1996, 06 (C8), pp.C8-59-C8-62. 10.1051/jp4:1996811 . jpa-00254539

\section{HAL Id: jpa-00254539 https://hal.science/jpa-00254539}

Submitted on 1 Jan 1996

HAL is a multi-disciplinary open access archive for the deposit and dissemination of scientific research documents, whether they are published or not. The documents may come from teaching and research institutions in France or abroad, or from public or private research centers.
L'archive ouverte pluridisciplinaire HAL, est destinée au dépôt et à la diffusion de documents scientifiques de niveau recherche, publiés ou non, émanant des établissements d'enseignement et de recherche français ou étrangers, des laboratoires publics ou privés. 


\title{
Effect of the Hydrogen Induced Degradation of Steel on the Internal Friction Spectra
}

\author{
E. Lunarska, Y. Ososkov and Y. Jagodzinski* \\ Institute of Physical Chemistry, Polish Academy of Sciences, 01-224 Warsaw, Ul.Kasprzaka 44/52, \\ Poland \\ * Institute of Metal Physics, National Academy of Sciences, Kiev, Ukraine
}

\begin{abstract}
The internal friction method was applied to study the process of the formation of hydrogen induced voids in a pipe line steel. Hydrogen precharging to a content, lower than that established in permeation tests as the critical one for void formation, affected the IF spectrum associated with the grain boundary relaxation. This implies the possibility for application of the mechanical spectroscopy methods for detection of initial stages of the hydrogen induced degradation of steels. The effect of hydrogen precharging on the grain boundary structure and on relaxation processes are discussed.
\end{abstract}

\section{INTRODUCTION}

Pipe line steel exposed to technological corrosive media or subjected to cathodic protection absorbs hydrogen. Hydrogen content $\left(C_{B}\right)$ higher than the critical one $\left(C_{v}\right)$ causes the formation of voids and crevices along the grain and phase boundaries. Detection of the change of the boundary structure preceding the crevice formation is of a great practical importance. Such a possibility provides the mechanical spectroscopy, since change of the grain boundary (GB) structure should modify the grain boundary relaxation (GBR) processes. On the other hand, the examination of steel with GB structure modified by hydrogen, without changing the phase morphology and chemistry may contribute to the understanding of still discussed [1] mechanisms of GBR.

In the present work, the irreversible effects of hydrogen precharging of ferrite-pearlite pipe line steel on GBR were studied using internal friction (IF) method.

\section{EXPERIMENTAL PROCEDURE}

Specimens were cut longitudinally from a pipe made of St.52.4 stee $10.22 \%$, $1.3 \% \mathrm{Mn}, 0.55 \% \mathrm{Si}, 0.035 \% \mathrm{~S})$ normalized at $1180 \mathrm{~K}$. The pearlite and ferrite grains (size of 10 to $15 \mu$ ) formed axial bands, about 351 wide (Figure 1 ). Pearlite ( $38 \%$ volume fraction) consisted of the ferrite and cementite lamellae about $1.3 \mathrm{~g}$ thick.

The critical hydrogen content, and the conditions for cathodic hydrogen charging to attain the different undercritical and overcritical hydrogen concentrations, were established in electrochemical measurements of hydrogen permeation [2] through the membrane made of studied stee] [3]. The results are shown in Table 1 . The critical hydrogen content $C_{v}$ was established as being $0.18 \mathrm{ppm}$.

After hydrogen charging, a 11 specimens were degassed in vacuum at $680 \mathrm{~K}$ for 3 hrs. Therefore, not the hydrogen-defects interaction, but the irreversible change of the structure due to hydrogen precharging was studied. 
For the comparison, the uncharged specimens were also subjected to the annealing at $680 \mathrm{~K}$ for $3 \mathrm{hrs}$. before the tests.

Table 1

The applied hydrogen charging conditions

\begin{tabular}{lccccc} 
state & $\begin{array}{l}\text { untreated } \\
\text { (annealed) }\end{array}$ & undercritical precharging & \multicolumn{2}{c}{ overcritical precharging } \\
parameters & A & B & C & D & E \\
$\mathrm{i}_{c}, \mathrm{~mA} / \mathrm{cm}^{2}$ & --- & 0.5 & 0.5 & 1.0 & 0.6 \\
$\mathrm{As}_{2} \mathrm{O}_{3}$ addition & -- & no & no & no & yes \\
time, hrs. & --- & 38 & 66 & 48 & 48 \\
$\mathrm{H}, \mathrm{ppm}$ & 0 & 0.08 & 0.14 & 0.44 & 1.00
\end{tabular}

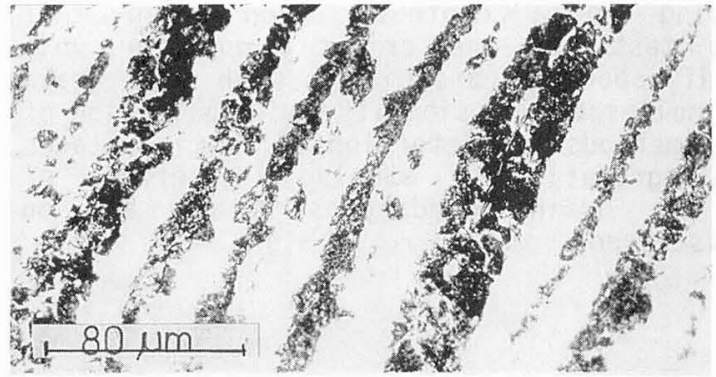

Figure 1. Microstructure seen on the longitudinal sections of studied steel.
IF measurements were done using an inverted torsion pendulum $(5 \mathrm{~Hz}$, 240 0e magnetic field, vacuum) at heating from $330 \mathrm{~K}$ to $1050 \mathrm{~K}$ with the rate of $2 \mathrm{~K} / \mathrm{min}$. The peaks were processed using Peakfit program (Jandel Sci. Co.) and lognormal distribution. The area beneath the peaks was considered as the peak intensity.

Tensile tests, OM and SEM observations were done for hydrogen precharged and degassed specimens.

\section{RESULTS AND DISCUSSION}

No change was observed at optical microscope examination of undercritically precharged and degassed specimens. However, after the tensile test of those specimens, microvoids (Figure 2a) were found on the fracture surface, not observed for untreated stee1. The void appearing at the ferrite-pearlite interface may suggest the decrease in the cohesion of those interfaces due to the undercritical hydrogen precharging.
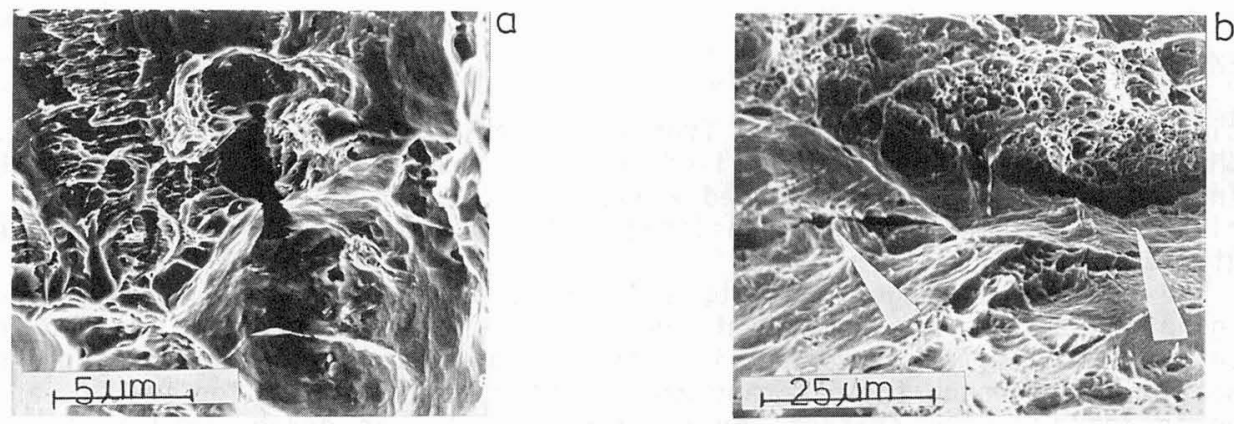

Figure 2. Fracture surface of hydrogen precharged, degassed, and then tensile tested steel: (a)-undercritical precharging; (b)-overcritical precharging 
Overcritically precharged, degassed and then tensile tested specimens exhibited the crevices exceeding the grain size (Figure $2 b$ ). Some microvoids along the pearlite bands were also found at microscopic observation of overcritically precharged, not strained steel.

In Figure 3 , the IF spectra (after substraction of background) recorded for specimens, untreated with hydrogen and for those precharged by hydrogen to the undercritical (Figure $3 a$ ) and overcritical (Figure $3 b$ ) state, and then degassed, are shown. It is seen that the grain boundary related If spectrum for studied steel in $A$ state is quite complex, revealing that several relaxation processes could be involved. If spectra recorded for specimens pretreated by hydrogen differed from those for untreated material. Since all the specimens were subjected to heating at $680 \mathrm{~K}$ for $3 \mathrm{hrs}$ before IF measurements, the differences should be accounted for the irreversible effects produced by hydrogen precharging on material structure. The ma in change caused by hydrogen pretreatment on If spectra was the increase in the height of maxima. It should be emphasized that modification of grain boundary If spectra by undercritical hydrogen pretreatment was much more significant than that produced by overcritical hydrogen precharging ( $c f$. Figures $3 a$ and $3 b$ ).

Studied ferrite-pearlite steel subjected to hydrogen charging is a very complex object. For understanding the obtained results, more information concerning the relaxation of different types of grain (phase) boundaries, as well as concerning the hydrogen effect on steel microstructure should be gathered. Below, the attempt to explain the obtained results is presented, although the authors realized that the discussion was rather oversimplified.

Processing of the spectra was done taking into account that in studied steel the boundaries between ferrite-ferrite, ferrite-pearlite and ferrite cementite existed (Figure 1). The results of the study of the effect of hydrogen precharging on the iron of high purity [4] were also utilized at the processing procedure. The example of deconvolution is presented in Figure 4. The change of the intensity of deconvoluted peaks due to the hydrogen precharging is shown in Figure 5 .

According to results obtained for pure iron [4], the low temperature $L$ and $H$ peaks (Figure 4) could be attributed to the relaxation of the ferrite-ferrite grain boundaries: the motion of near GB dislocations [4], and the sliding along GB [5] were assumed to be responsible for peaks $L$ and $H$, respectively. Increase in the intensity of peak $L$ at low undercritical state (Figure 5) could be caused by an increase in the number of dislocations near GB due to the hydrogen precharging. Formation of more and more complex dislocation network at increasing precharging caused the decrease in the anelastic response of dislocation loops, and thus the decrease in the intensity of peak L. At high overcritical precharging, the annihilation of dislocations into the formed ferrite-pearlite intergranular crevices (Figure 2b) might also affect the relaxation process.

Peak $\mathrm{H}$ attained the minimum intensity (and temperature) at precharging close to the critical one; overcritical pretreatment caused the pronounced increase in peak intensity (Figure 5). Since hydrogen induced crevices occurred along the ferrite-pearlite bands (Figure 2), intensification of the ferrite-ferrite grain boundary sliding might be expected at overcritical charging, because it was not restrained by the pearlite bands any more.

Peaks 2 and 3 appearing at the high temperature side of IF spectra (Figure 4), and not observed in the case of pure iron [4] could be accounted by the relaxation of the other grain (phase) boundaries present in the steel.

Undercritical treatment increased the peak 2 (Figure 5). Since the voids formed at the boundaries between the ferrite and pearlite bands (Figure 2), the preceding change of metal structure should affect the relaxation at these boundaries. This may suggest the relation of peak 2 to the relaxation at ferrite-pearlite grain boundaries. Peak 3 might be associated with the relaxation at the boundaries between the ferrite and cementite lamellae, a) though the other relaxation processes could be involved. 

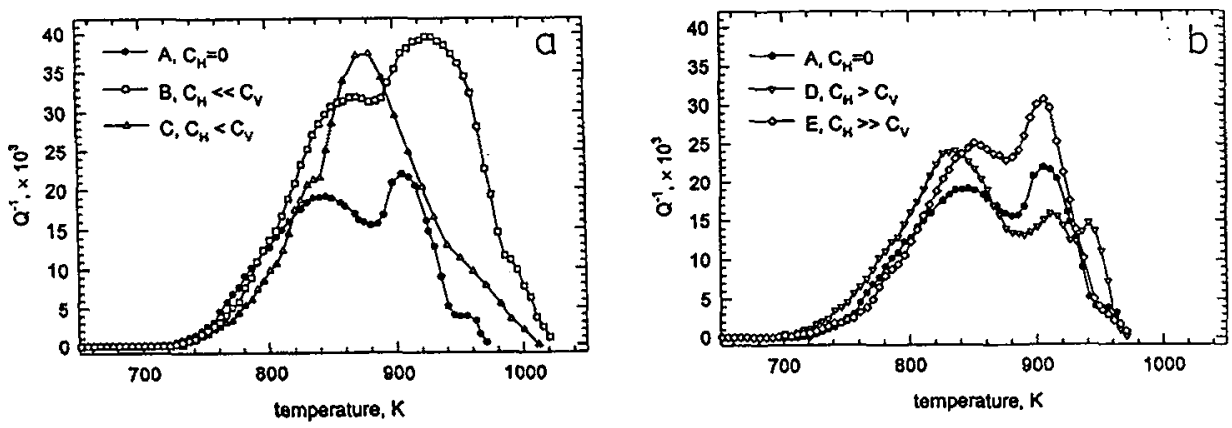

Figure 3. Typical examples of IF spectra (after background subtraction) obtained for untreated steel $\left(C_{\mathrm{B}}=0\right)$ and for degassed samples precharged with hydrogen to undercritical (a) and overcritical (b) content.
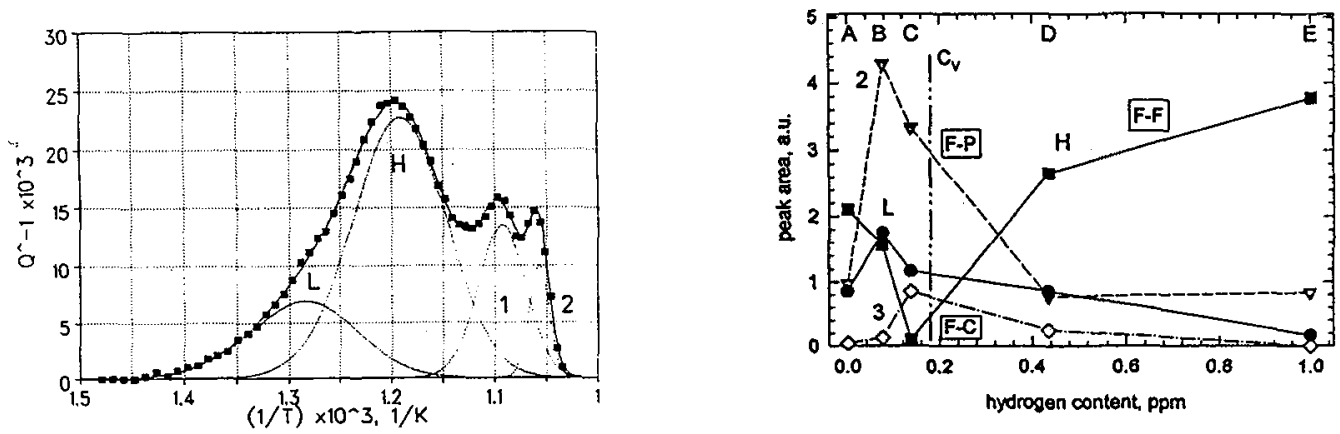

Figure 4. Example of deconvolution of IF spectrum (specimen in state D).

Figure 5. Change of the intensity of deconvoluted IF peaks, depending on hydrogen precharging. Critical content is marked.

\section{CONCLUSION}

Hydrogen precharging of ferrite-pearlite pipe line St.52.4. steel to the content lower that the established critical concentration for GB void formation caused irreversible changes of GB structure, which could be detected by mechanica 1 spectroscopy methods.

\section{Acknow ledgements}

The work was supported by Polish grants KBN 7S 20301906 and Z/5310/95/3985

\section{References}

[1] Molinas B.J. and Povolo F., Mater. Sci. Forum, 119-121 (1993) 39-45

[2] Devanathan M.A.V. and Stachurski Z. , Proc. Roy. Soc., 270 (1962) 90-103

[3] Ososkov Y., Ph.D. Theses, Warsaw Technical University, 1996

[4] Lunarska E., Jagodzinski Y., Ososkov Y., Phys.Stat.Sol.(a) 156 (1996) 343

[5] Ke T.S., Scripta Metal7. Mater., 24 (1990) 347-352 